I last heard of him, in June, he had shaken off the cerebral symptoms, and was so much better in every way that he was returning to business, from which he had definitively retired.

I have now under observation a lady, the wife of a medical man, in whom I predicted cerebral hæmorrhage, and in whom also it has occurred. She suffered from violent palpitation, faintness, and feeling of lowness, for relief from which she had resorted to stimulants. She had also become weak and liable to attacks of vertigo. From this and from timidity she had almost entirely given up out-door walking. I never met with a case of such extreme high tension. The pulserate was habitually nearly 120, the arteries everywhere prominent and tense. She had a rather bloated, red face, which was still more disfigured by acne; and her aspect was that of extreme plethora. I obtained by much urging a modification of her diet, but I could not prevent recourse to stimulants, which were not, however, taken to excess. only saw her twice, early in the year, but felt certain of the condition which threatened her, and gave a prognosis of apoplexy. In May she had her first distinct warning, which came in the shape of hæmorrhage into the left retina, with loss of sight. In June she had more severe and alarming symptoms, a meningeal hæmorrhage having apparently occurred. On the night of the 6 th she became restless and irrational in her talk, and then a severe attack of convulsions came on; she had altogether four attacks of convulsions within twelve hours, which were followed by prolonged loss of consciousness, and when recovering from this she was in a state of extreme excitement, with delirium and delusions and complete loss of memory; she became also extremely obstinate and violent.*

But, besides furnishing a basis for prognosis, arterial degeneration often explains to us a long train of miserable nervous symptoms coming on late in life-loss of energy, depression of spirits, a feeling of confusion in the head, sleeplessness, transitory loss of consciousness. I have in mind the case of a lady for some time under my care, formerly energetic, active, full of spirits, now prostrated or confused by the slightest exertion, bodily or mental, scarcely able to walk, or to write a letter, or to command her attention, sleepless, and persecuted by a constant pain in the back of the head. She is relieved by the very means which her weak state would seem to contra-indicate.

You have seen also in two cases, one still in the hospital, the other only just discharged, how convalescence from slight illness has been protracted almost indefinitely for no assignable reason except that the arteries were degenerated. In one, however, the heart was weak, and till restored by prolonged rest in bed its systole gave neither impulse nor first sound. Both the patients were women, who, nearly up to the time of admission, bad been able to attend to their duties, and both came in for subacute rheumatism. The first, a monthly nurse, aged fifty-seven, had a slight attack of pneumonia a few days after her admission, but this did not at all account for her extreme weakness and slowness in recovery. It was more than three months before she could stand, and when she left the hospital, at the end of four months, she could only just walk the length of a small ward. The arteries were small, irregular, resistant, certainly de. generated, perhaps on the way to calcareous change; and this, I think, explained the difficulty attending the reestablishment of the nutrition and restoration of strength. The case of the other patient was very similar, and I need not give the particulars.

When advanced calcareous degeneration of the small arteries exists it can scarcely escape attention, even on the most superficial examination. The radial feels, as I bave said more than once, like a string of small beads when the fingers are carried with the skin along its length. All I need do is to remind you that with the vessels in this condition a very slight ailment may prove fatal. I have had no marked instance in the wards lately, and to read you notes of cases I have had under observation formerly would simply be to give you accounts of the complications by which the patients were carried off. In one the chain of events was bronchitis, œdema of feet gradually progressing to general dropsy, failure of right heart with enlarged liver, and albuminuria. In another, attacks of giddiness, loss of energy and memory, indistinct and slow articulation, later a gradual impairment of the faculties, occasional escape of urine and frees in bed or into clothes, and ultimately the entire train of symptoms attending cerebral sof tening.

I propose to take up this subject again on another occasion, for I find I have not time to complete it to-day. It is not merely in forming prognosis that a careful study of the indications furnished by the pulse is useful, but also in treatment, and of this I hope to give illustrations.

\section{ON A \\ NEW URETHROTOME FOR INTERNAL URETHROTOMY.}

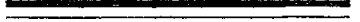

BY PATRICK HERON WATSON, M.D., F.R.S.E., \&c., SENIOR SURGEON TO THE ROYAL INFIRMARY, EDTNBURGH.

I IAVE no wish to enter into any consideration at present of the advantage of one method of treating stricture of the urethra as compared with another. I believe that dilatation, divulsion, external and internal urethrotomy, have each their separate sphere, and form an efficient armoury, from which a skilled surgeon will, according to circumstances, select his appropriate weapon. I wish at present merely to direct attention to a new instrument which two years ago I had constructed for the internal division of strictures of the urethra. It has seemed to me much more satisfactory than any other form of instrument, intended to effect internal urethrotomy, with which I am acquainted.

The original instrument I had constructed for me in Paris under the direction of my former resident surgeon, $\mathrm{Mr}$. C. W. Macgillivray, by Luer of Paris, but as its size was too large for the treatment of very tight strictures, I bad a modified instrument, upon the same principle, constructed by Mr. Young of this city. From the accompanying woodeut it

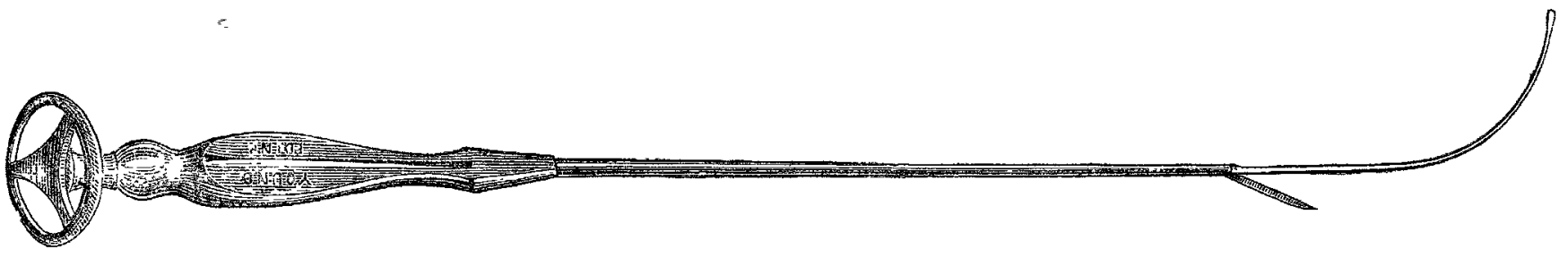

* The treatment consisted chiefly in free purgation. Venesection was to have been practised had convulsions again come on. Bromide of ammonium was given for a short time. A farinaceous, milk, and fish diet was prescribed and stimulants forbidden. When this lecture was delivered, the menta powers appeared to be so much shaken that anything like complete recovery was searcely hoped for, especially as improvement of intellect did not at al keep pace with the improvement in the patient's general condition. 'To my astonishment, the arterial tension was gradually reduced, the pulse became perfectly soft and natural, without being weak, and the rate came down to 72. The arterial degeneration I had diagnosed did not, in fact, exist; and I think the tension, which was quite the most remarkable $I$ ever met with, was due to the frequent and powerful action of the heart, which forced blood into the arterial system faster than it could escape by the capillaries, except under great pressure. For some weeks the behaviour was peculiar and memory all but lost. Now, however (July 12th), except that the memory is still weak, the patient is well.

will be seen to consist essentially of a Syme's stricture staff, from which a tenotomy blade is made to protrude at an angle on turning from left to right $a$ wheel fixed at the proximal extremity of the instrument. This instrument is probe-pointed at the distal extremity, and the size of a No. 10 or 12 at the haft. The instrument gradually increases for four inches from the fine probe-pointed extremity, up to the size of a No. 2 bougie. Here it abruptly enlarges to the size of a No.12. At this point, where the thick and thin portions of the instrument are continuous, a tenotomy knifeblade, concealed in a groove in the slender part of the shaft, is so pivoted that it can be projected at an angle with the commencement of the thick portion of the staff. The degree 
of angular projection of the knife is determined by the number of turns given to the screw attached to the handle of the instrument, and this degree of protrusion is marked by an indicator on the sbaft. For the purpose of cleansing the instrument after use, the blade can be screwed out to a right angle to the shaft; but in use, when dividing a stricture, no protrusion beyond an angle of $45^{\circ}$ is required. The instrument in all its parts, except the blade, is nickelised to prevent rusting.

When employed the instrument is introduced with the blade enclosed in its groove. When the pointed extremity has been insinuated through the strictured part of the canal, it glides smoothly onwards towards the bladder, till the anterior extremity of the stricture arrests the progress of the thick portion of the staff. The anterior extremity of the stricture is thus determined with absolute precision, and as few strictures exceed an inch and $a$ half in length, the blade is sufficiently long to secure the division of the stricture with one movement of withdrawal of the whole instrument. When once the instrument has been lodged in close contact with the stricture, the screw in the handle is turned so as to secure a protrusion of the blade to an angle of $30^{\circ}$, the whole instrument is then drawn forward as if to withdraw it from the canal. When this is at first attempted it is felt to be firmly held, then the tissues yield. When the instrument has been withdrawn about two inches from the urethra, the screw is inverted, causing the blade to retreat completely into its groove, and the passage of the whole instrument onward towards the bladder is once more attempted. In most instances this is found unopposed. And if it be so, the urethrotome is withdrawn, and a full-sized catheter passed to empty the bladder. Should the passage onwards of the thick portion of the instrument be opposed, either another stricture or some portion of the same stricture is shown to be undivided. A reprotrusion of the blade, and repetition of the movement of withdrawal, will secure the division of this obstruction, and similarly of any other constriction which may still oppose the passage of the full-sized portion of the stem of the instrument.

I have never encountered any troublesome homorrhage in the use of this instrument, while by means of it the extent of tissue divided has always been completely under control.

The woodcut shows very well the appearance of the instrument with the blade protruded at an angle of about $20 \mathrm{deg}$.

The advantages which this instrument has seemed to me to present are: -1 . It determines accurately the anterior aspect of the stricture, while the shaft has been insinuated through the contraction. 2. It divides the stricture from behind forwards. 3. It enables the operator, by the abrupt shoulder on the shaft, to determine whether, by the use of the cutting apparatus, the stricture has been completely or only partially divided, and admits of his completing the division if need be, without any change of instrument, by merely repeating the same steps of operative procedure, as in the first instance. 4. It limits the section of the urethra to the part or parts which are actually contracted, and does not "promenade" the whole canal. 5. Its use is attended by remarkably little pain or bleeding.

As the arrangement of the wheel and screw admits of no yielding of the blade, even in fibrous, cartilaginous, or resilient structures, in which cases I have chiefly employed it, the section of tissue is effected with absolute certainty, the gradual angle or wedge-forming position of the knife to the stem of the instrument securing that the cutting edge will act against all tissues with which it is brought in contact as the instrument is withdrawn. Neither have I found any difficulty in retiring the blade within its groove when the section is complete, the fitting of the parts securing them against the possible interposition of any portion of the surfaces of the divided soft tissues.

For strictures situated in the anterior portion of the urethra, an instrument constructed precisely in the same manner, but shorter and quite straight, is made. I find myself, however, that the ordinary curved instrument is quite sufficient for every purpose.

The cutting-blade has its edge turned towards the floor of the urethra, but it may be constructed to act upwards if so desired, or to work with a double-edged knife, both upwards and downwards. I prefer myself that the incision should be made only in one direction, and that downwards or towards the floor of the canal.

Edinburgh

\section{CASE OF MEDIASTINAL TUMOUR.}

BY THOMAS COLE, M.D., M.R.C.P.,

IPHYSICIAN TO THE BOYAL UNITED HOSPTTAL, BATE.

I AM indebted to $m y$ friend and house-physician, Mr. Field, for most of the notes of the following case.

William I- aged fourteen, a traveller, was admitted into the Royal United Hospital, Bath, on Aug. 9th, 1875.

History.-With the exception of being in a London hospital some time since, for some weeks, he gives no account of illness till three weeks ago. He then had an eruption on the right lip, with a barking cough. A week afterwards he ran, in the early morning, after a stray horse, and fell down all bathed in perspiration. A week ago he was wrestling with a playmate, when he suddenly became breathless, but felt no pain. Since that time the breathing has been so difficult that he could not lie down in bed; last night he could not go to bed at all. He has been very thirsty for three weeks, with a bad appetite and confined bowels.

Present condition.-Respiration most painfully laboured, not much quickened; slight cough ; tongue furred; no marked blueness of face; heart apparently healthy. Dulness at right lung-apex anteriorly, and at posterior left base; at the latter spot tubular breathing; on both sides anteriorly, except at the extreme left apex, the breathing is very indistinct, very little air seeming to enter the chest. Expiration prolonged everywhere; no crepitation nor rhonchus. Liver two inches below the costal margin; spleen not enlarged. Temperature at 9 P.M. $99^{\circ} \mathrm{Fahr}$.; respiration 32 ; pulse 134 . Ordered, three grains of carbonate of ammonia, half a drachm of compound camphor tincture, and ten minims of tincture of squill, to an ounce of water, every four hours.

Aug. 10th.-Temperature $986^{\circ}$; respiration 33 ; pulse 122 , small and weak. Passed a dreadful night, wanting to get in and out of bed; orthopnca ; face bedewed with perspiration lips somewhat blue; external jugulars swollen, the left more than the rigbt; superficial veins on the right side of the chest prominent and enlarged; tenderness over this part; much heaving of the chest on inspiration; a few small cervical glands enlarged; total dulness in the right anterior chest, including the sternal region; but little movement; nearly the same on the left side; fremitus diminished, except at the lower right half; vocal vibration diminished. Right chest posteriorly: a tympanitic note everywhere except at a point behind the infra-axillary region, where there is dulness; loud blowing breathing all over. Left chest posteriorly: hyper-resonant superiorly; dull, with a tympanitic modification, below; vocal fremitus much diminished below, somewbat increased above. Tubular breathing heard generally, with a little small crepitation. The diagnosis now arrived at was, that the patient was suffering from a tumour in the anterior mediastinum, malignant in its nature, and probably of a lymphadenomatous character. Evening temperature $996^{\circ}$; respiration 36 ; pulse 136 ; urine acid, sp. gr. 1027, loaded with pink and white lithates, no albumen.

11th.-Morning temperature $98.4^{\circ}$; respiration 30 ; pulse 124; very bad night; constant orthopnoa; temperature, according to the nurse, was $103^{\circ}$ at $8^{-} \mathrm{A} . \mathrm{M}$.; tongue much coated; sweating profusely; takes scarcely any food; no excess of white blood-cells.-Evening: Temperature $1004^{\circ}$, respiration 40 , pulse 142 . Ordered ten grains of chloral.

12th.-Temperature $986^{\circ}$, respiration 36 , pulse 140 ; slept about two hours after a second dose of chloral; no improvement; there was evidence of a larger accumulation of fluid in the pleural cavities.-Evening: Temperature $994^{\circ}$, respiration 40, pulse 146. Death somewhat suddenly ended the poor lad's sufferings the same night.

Post mortem examination.-On opening the chest a large quantity of serous fluid escaped from both pleural cavities; on the right side it was confined to the anterior two-thirds of the chest by old firm adhesions, and the lung was bound down in a carnified state at the back; on the left side the carnified lung floated freely in the fluid. The lungs were free from growth, except a few white grains on the pleural surface. Beneath the costal pleura, and situated over the ribs, were masses of new growth ; these were at the posterior part of the chest, and quite removed from the main mass 